\title{
Predictors of High Risk Coronary Artery Disease In Subjects with Normal SPECT Myocardial Perfusion Imaging
}

\author{
Rine Nakanishi, MD PhD*, Heidi Gransar, MS*, Piotr Slomka, PhD*, Reza Arsanjani, MD*, \\ Aryeh Shalev, MD*, Yuka Otaki, MD PhD*, John D. Friedman, MD*, Sean W. Hayes, MD*, \\ Louise E. B. Thomson, MBChB", Mathews Fish, MD§, Guido Germano, PhD*, Aiden Abidov, \\ MD PhDI, Leslee Shaw, PhD\#, Alan Rozanski, MD ${ }^{\ddagger}$, and Daniel S. Berman, MD ${ }^{\star}, \dagger$ \\ *Departments of Imaging and Medicine, Cedars-Sinai Heart Institute, Cedars Sinai Medical \\ Center, Los Angeles, California; \\ $\S$ Oregon Heart and Vascular Institute, Sacred Heart Medical Center, Springfield, Oregon; \\ ISarver Heart Center, University of Arizona College of Medicine, Tucson, Arizona.: \\ \#Department of Medicine, Emory University, Atlanta, Georgia: \\ ‡Division of Cardiology, St. Luke’s Roosevelt Hospital, New York, New York. \\ tDepartment of Medicine, David Geffen School of Medicine, University of California, Los Angeles, \\ California, USA;
}

\section{Abstract \\ Background: While uncommon, normal stress SPECT myocardial perfusion imaging (MPI) can be seen in patients with high-risk coronary artery disease (CAD) by invasive coronary angiography (ICA). The predictors of high risk CAD in patients with normal SPECT-MPI have not been described.}

Methods: We studied 580 patients (age $64 \pm 12$ years, $49 \%$ men) without known CAD who underwent stress gated SPECT-MPI [exercise (41\%) or vasodilator (59\%)] $<2$ months before ICA and had summed stress score (SSS) <4. High risk CAD was defined as 3 vessels with $\geq 70 \%$ stenosis, 2 vessels with $\geq 70 \%$ stenosis including proximal left anterior descending, or left main with $\mathbf{2 5 0 \%}$ stenosis. Obstructive non-high risk CAD was defined by the presence of a $\geq 70 \%$ stenosis but without having other high risk criteria. Ten-fold cross-validated receiver operating characteristic (ROC) estimates were obtained to assess the predictors of high risk CAD.

Results: Forty-two subjects (7.2\%) had high-risk CAD and 162 had obstructive non-high risk CAD. Variables associated with high risk CAD were pretest probability of CAD $ð 66 \%$ (Odds ratio [OR] 3.63, 95\% CI1.6-8.3, p=0.002), SSS >0 (OR7.46, 95\% CI2.6-21.1, p<0.001) and abnormal TID (OR2.16, 95\% CI1.0-4.5, p=0.044). When substituted for TID, EF change was also predictive of high risk CAD (OR0.93, 95\% CI0.9-1.0, $\mathrm{p}=0.023$ ). The prevalence of high risk CAD increased as the number of these predictors increased. In a sub-analysis of patients in whom quantitative

Address for correspondence: Daniel S. Berman MD FACC, Department of Imaging and Medicine, Cedars-Sinai Heart Institute, Cedars-Sinai Medical Center, 8700 Beverly Boulevard, Los Angeles, California 90048, Tel: +1-310-4234223, Fax: +1-310-4230811, bermand@cshs.org. 
total perfusion deficit (TPD) was available, TPD $>0$ was also a predictor of high risk CAD

(OR6.01, 95\% CI1.5-22.2, p=0.011).

Conclusion: Several clinical, stress and SPECT-MPI findings are associated high risk CAD among patients with normal SPECT-MPI. Consideration of these factors may improve the overall assessment of the likelihood of high risk CAD in patients undergoing stress SPECT-MPI.

\section{Keywords}

Single-photon emission computed tomography myocardial perfusion imaging; SPECT-MPI; High risk of coronary artery disease

\section{Introduction}

In the last few decades, single-photon emission computed tomography (SPECT) myocardial perfusion imaging (MPI) has become widely used worldwide for risk stratification and guiding management of patients with suspected or known coronary artery disease (CAD) ${ }^{1}$. A normal SPECT-MPI examination is well established as being associated with a very low risk of cardiac events ${ }^{2}, 3$. However, an underestimation of the presence of high risk anatomic CAD by SPECT-MPI has also been well described ${ }^{4,5}$. In part, this has been attributed to the reliance of the method on relative perfusion defects in the myocardium compared to more normal zones ${ }^{4-6}$. The possibility of having a normal test result in a patient with high risk angiographic findings can be clinically problematic with respect to guiding decisions regarding the need for invasive coronary angiography in an individual patient. Features that might be suggestive of "false negative" SPECT MPI studies for high risk CAD could be of clinical use; however, such predictors have not been well examined to date. The purpose of this current study is to investigate whether clinical and stress variables are predictive of the possible presence of high risk CAD among subjects with normal SPECT-MPI.

\section{Methods}

\section{Study population (Figure 1)}

We studied patients undergoing clinically indicated exercise or pharmacologic stress SPECT-MPI at Cedars-Sinai Medical Center between 1994 and 2005 and Sacred Heart Medical Center (Eugene, Oregon) between 2003 and 2006. Of 29,851 patients without known CAD, 25,698 patients had normal SPECT-MPI studies defined as summed stress score (SSS) <4. Of these, 580 patients (mean age $64 \pm 12$ years, $49 \%$ men) including 363 patients from Cedars-Sinai and 217 patients from Sacred Heart subsequently invasive coronary angiography (ICA) within 60 days and were the subjects of this study. No patients had cardiac events between ICA and SPECT. This study was approved by the Institutional Review Board of Cedars Sinai Medical Center and Sacred Heart Medical Center.

\section{Risk factor assessment}

CAD risk factors incorporating hypertension, diabetes, current smoking, hypercholesterolemia, and family history of premature CAD were documented ${ }^{7}$. Symptoms of chest discomfort were classified as described by Diamond and Forrester ${ }^{8,9}$. Typical chest 
pain was defined as chest pain that was substernal, occurred during physical or emotional stress, and resolved with rest or nitroglycerin. Chest pain was classified as atypical angina if individuals had chest pain with two of the three above characteristics. Nonanginal chest pain was defined if subjects experienced chest pain with none or one of these 3 features. Based on symptoms, age and gender, pretest probabilities of CAD were calculated and classified into low $(<15 \%)$, intermediate $(15-65 \%)$ and high-intermediate/high $(\checkmark 66 \%)^{10}$.

\section{Imaging and stress protocol}

Whenever possible, beta-blockers and calcium channel antagonists were terminated $48 \mathrm{~h}$ before testing and nitrates at least $6 \mathrm{~h}$ before testing. Patients were injected intravenously at rest with Tl-201 $(\mathrm{n}=363)$ or Tc-99m $(\mathrm{n}=217)$ and SPECT was initiated 10-60 minutes after injection and performed as previously described ${ }^{11,12}$. Symptom limited exercise or adenosine with or without low-level treadmill exercise protocols were then performed with stress injection of Tc-99m sestamibi ${ }^{11}, 13,14$. Twelve-lead electrocardiography (ECG) was monitored continuously during stress tests. Heart rate (HR) and blood pressure were recorded at baseline and every minute for at least 5 minutes after stress.

Gated SPECT imaging was initiated 15-30 minutes after exercise or 30-60 minutes after adenosine stress, employing 180 degree acquisition for 64 projections and low energy, high resolution collimators. Images were acquired with either combined supine and prone imaging (Cedars-Sinai) or attenuation correction (Sacred Heart) ${ }^{2}, 12$ using the Vantage Pro AC hardware and software. Tomographic reconstruction and reorientation was performed by AutoSPECT ${ }^{15}$ and Vantage Pro AC programs.

\section{SPECT Imaging Assessment}

Semi-quantitative visual interpretation was performed using the 17 -segment model ${ }^{16}$. Each segment was scored using the 5 -point scoring system $(0=$ normal, $1=$ equivocal, $2=$ =moderate, $3=$ severe reduction of uptake, and $4=$ absence of detectable tracer ${ }^{13}{ }^{17}$. Summed stress scores (SSS) were obtained by adding the scores of the 17 segments. Studies with SSS <4 were defined as normal SPECT-MPI (4). In 390 patients with available quantitative data, the total perfusion deficit (TPD), assessing both defect extent and severity of perfusion defects, was calculated as the percentage of the total surface area of the left ventricle of which test data were below the predefined uniform average deviation threshold when compared to normal limits, using normal limits and a previously developed simplified approach ${ }^{18}$. TPD was derived from the combined supine and prone images datasets as previously described ${ }^{19}$ or from the attenuation corrected data. Briefly, an ellipsoidal model and contours derived by the quantitative perfusion SPECT algorithm ${ }^{20,21}$ were used to extract polar map samples. Transient ischemic dilatation (TID) of the left ventricle was calculated by the software from the three-dimensional LV volumes from the non-gated SPECT images ${ }^{22}$. Normal or abnormal TID was defined by previously reported thresholds for exercise or pharmacologic stress and the different SPECT agents ${ }^{23}$. Stress and rest left ventricular ejection fraction (EF) were automatically calculated by quantitative gated SPECT using the volume-based approach as previously described ${ }^{24}$. Abnormal EF/EF response during stress was defined as a decrease of $\geq 5 \%$ from rest and stress or a post-stress EF of $<43 \%$ in men and $<51 \%$ in women ${ }^{25}$. 


\section{Coronary angiography and angiographic risk groups}

All subjects underwent invasive coronary angiography (ICA) within 60 days after SPECT testing. The degree of coronary stenosis was estimated visually by experienced cardiologists. The patients were divided into three angiographic risk groups. Forty-two subjects (7.2\%) had high risk CAD (high risk CAD group) as defined by a modified Duke CAD prognostic index ${ }^{26}$, which included patients with one of the following: 3 vessels with $\geq 70 \%$ stenosis, 2 vessels with including the proximal left anterior descending (LAD), or left main (LM) with $\geq 50 \%$ stenosis. One hundred sixty-eight subjects $(29.0 \%)$ had at least one $\geq 70 \%$ stenosis without being in the high risk group (obstructive non-high risk CAD group), and 370 subjects $(63.8 \%$ ) did not have a $\geq 70 \%$ stenosis or a $\geq 50 \%$ LM stenosis (no CAD group). The 42 high risk CAD group was further analyzed for patterns that might be associated with balanced (LM disease + RCA, or 3VD) or non-balanced (LM without RCA, or 2VD including proximal LAD) reduction of blood flow.

\section{Stress characteristics}

In patients undergoing exercise testing, HR reserve was calculated as ([peak HR - rest HR]/ [220 - age - rest HR] $\times 100$ ), with $<80 \%$ considered abnormal ${ }^{27}$. Exercise workload (METs) and duration were evaluated ${ }^{28}$. Maximum predicted heart rate (MPHR) was calculated as (220-age). Among patients undergoing pharmacologic stress, the HR ratio (peak/rest HR) was calculated, with $<1.12$ considered abnormal ${ }^{29}$.

Abnormal ECG response was defined based on the degree of ST-depression on stress ECG or the development of ventricular tachycardia. Abnormal clinical exercise response was defined as chest discomfort, development of an angina equivalent, or exertional hypotension during stress testing. Since chest discomfort and blood pressure fall are commonly seen as a normal response to adenosine, no abnormal clinical response to adenosine stress was described.

\section{Statistical analysis}

Continuous variables were expressed as the mean \pm standard deviation. The unpaired Student's t-test (for normally distributed variables) or the Wilcoxon rank-sum test (for nonparametrically distributed variables) was used to conduct the no CAD, obstructive non-high risk $\mathrm{CAD}$, and high risk $\mathrm{CAD}$ group comparison. Categorical variables were compared using Pearson Chi-squared tests or Fisher exact test for cell counts $<6$.

Ten-fold cross-validated area under the curve (AUC) by receiver operating characteristic estimates were obtained to assess whether clinical, stress and SPECT-MPI variables including pretest probability of CAD $₫ 6 \% \%$, stress ECG response, SSS, and EF change or TID predict obstructive non-high risk CAD, or high risk CAD. In sub-analysis of 390 patients with TPD, we also assessed whether the same model using TPD in place of SSS.

All statistical calculations were performed using STATA (Version 11, StataCorp LP, College Station, Texas, USA) for Windows. P-values $<0.05$ were considered statistically significant and only two-sided tests were conducted. 


\section{RESULTS}

\section{Clinical and angiographic characteristics}

The prevalence of CAD findings between Cedars Sinai Medical Center and Sacred Heart Medical Center were similar (no CAD: $66.9 \%$ vs. $58.5 \%$, obstructive but non-high risk CAD: $26.7 \%$ vs. $32.7 \%$, high risk CAD: $6.3 \%$ vs. $8.8 \%$ in the Cedars-Sinai and Sacred Heart populations, respectively; $\mathrm{p}=0.12$ for all). Baseline characteristics and angiographic findings are shown in Table1. Compared to the subjects with obstructive non-high risk CAD or high risk $\mathrm{CAD}$, subjects with no CAD were older and more commonly male. More had hypertension, hypercholesterolemia or greater number of CAD risk factors and presented with typical angina chest pain compared to those without obstructive CAD. BMI and other CAD risk factors including diabetes, smoking and family history did not significantly differ between the three groups. Patients with high risk CAD had a higher prevalence of highintermediate/high pretest probability of CAD than those with no CAD or obstructive nonhigh risk CAD (Table1).

Overall, 210 patients (36.2\%) had obstructive CAD (any vessel with $\geq 70 \%$ stenosis or LM $250 \%$ stenosis). Of the 168 patients in the obstructive non-high risk CAD group, 114 patients had 1VD (19.7\%) and 50 patients had 2VD (8.6\%). The 42 patients with high risk CAD included 22 patients with LM disease (3.8\%) (3 patients with LM only, 7 patients with LM plus $3 \mathrm{VD}$ and 12 patients with LM with 2VD or 1VD), 12 patents with 3VD without LM (2.1\%), and 8 patients with 2 vessels with $\geq 70 \%$ stenosis including proximal of LAD with $\geq 70 \%$ stenosis (1.4\%) (Table 1). Three patients with LM only had $70-85 \%$ stenosis in the LM; of these, one patient underwent PCI, and one patient had coronary artery bypass surgery within one week after ICA, and one patient with lung cancer did not undergo any revascularization.

\section{Stress Test Characteristics}

Of the 580 patients, 154 (41\%) had exercise stress and 216 (59\%) underwent pharmacologic stress. Stress type was not different between the three angiographic groups (no CAD vs. obstructive non-high risk CAD vs. high risk CAD: $41.6 \%$ vs. $38.1 \%$ vs. $42.9 \%, \mathrm{p}=0.67$ ). Table 2 shows stress characteristics among patients who had exercise stress in the three groups. Baseline hemodynamics did not differ between three groups. During exercise, there was no significant difference systolic BP, HR, change of BP and HR, HR reserve and \%MPHR between three groups. Patients in the high risk CAD group showed lower Duke treadmill score, shorter exercise duration and greater fall in EF compared to those in no CAD group. Table 3 shows stress characteristics among patients with pharmacologic stress in the three groups. While baseline and after stress hemodynamics did not differ between three groups, patients with high risk CAD had a higher prevalence of abnormal ECG response compared to those with no CAD. There was a greater negative change from rest to stress of $\mathrm{EF}$ among subjects with high risk CAD than among those without high risk CAD.

\section{SPECT-MPI Characteristics}

The SPECT-MPI characteristics of the three groups are shown in Table 4. There was a progressive increase in SSS and SDS across the three angiographic groups, with the highest 
being in the high risk group. Patients with high risk CAD had a higher prevalence of abnormal TID than those with no CAD $(45.2 \%$ vs. $26.9 \%$, p $<0.05)$ (Table 4$)$. The prevalence of SSS 0 and 1-3 among the three groups is shown in Figure 2. Only 7 (16.7\%) of patients with high risk CAD had SSS zero, compared to $57 \%$ of those with no CAD. The frequency of SSS 0,1 or 2 and 3 scores in 42 patients with high risk CAD stratified by anatomic findings that might be associated with balanced ischemia is shown in Figure. Twenty-six of the 42 patients were in the balanced anatomic group and 16 were in the non-balanced group (LM without RCA, or 2VD including proximal LAD). Six of the 7 patients with SSS 0 were in the balanced group.

\section{Ten-fold cross validation of clinical, stress and SPECT-MPI characteristics to predict high risk CAD.}

Table 5 demonstrates two models of ten-fold cross validation of clinical, stress and SPECTMPI characteristics to predict high-risk CAD or obstructive non-high risk CAD. Highintermediate pretest probability of CAD and SSS predicted obstructive non-high risk CAD [Model 1; AUC=0.61 (0.56-0.66)] or high risk CAD [Model 1; AUC=0.75 (0.67-0.84)]. TID ratio demonstrated a predictor of high risk CAD (OR 2.16, 95\% CI 1.0-4.5, $\mathrm{p}=0.04$ ). No such trend was seen for the association of TID with obstructive non-high risk CAD (OR $1.34,95 \%$ CI 0.9-2.1, $\mathrm{p}=0.771$ ). When EF change instead of TID ratio was included in the model, the predictors of high risk were similar, including the EF change (Model 2). In subanalysis of 390 patients who had available data of TPD, the predictors were similar, with TPD being one of the significant predictors of both high risk CAD and obstructive non-high risk CAD (Table 6, Model 1 and 2).

\section{The relationship between high risk CAD and predictors}

Based on the models, three variables were considered as predictors of high risk CAD: SSS 1-3 (perfusion), TID and/or abnormal EF/EF response (function), and pre-test likelihood of CAD $266 \%$. The prevalence of high risk CAD increased as the number of these predictors increased (Figure 4). High risk CAD was seen in 11/452 (2.4\%) with 0-1 predictor, 22/163 $(13.5 \%)$ with two predictors and $9 / 35(25.7 \%)$ of patients with 3 predictors. Only three of the high risk CAD patients (7.1\%) had none of these predictors.

\section{Discussion}

The presence of normal SPECT examinations in patients with high risk CAD at subsequent coronary angiography not infrequently confronts the physician interpreting or using the results of SPECT-MPI. The current study was undertaken to determine if there were features on "normal" SPECT-MPI examinations, including clinical, stress and SPECT-MPI test findings, which were associated with the presence of high risk CAD. In this study high risk CAD was found in 42/580 patients (7.2\%) undergoing ICA within 60 days after normal SPECT-MPI. We found that pretest probability of CAD $\searrow 66 \%$ was predictive of high risk CAD. Further, although all of the patients had "normal" SPECT-MPI, variables from the MPI examination were predictive of high-risk CAD including mild/equivocal perfusion defects which were too minimal to meet criteria for abnormality, a high TID ratio or abnormal EF/EF response were also significant predictors. 
Several studies have shown that SPECT-MPI examinations may underestimate the extent of anatomic $\mathrm{CAD}^{4,5}$. Previously, our group investigated the relation of $\mathrm{LM}$ disease to the extent of SPECT-MPI findings among 101 patients with LM disease ${ }^{4}$. In that study, only $56 \%$ of the patients were identified as having high risk CAD on the basis of $10 \%$ stress perfusion defect. However, after consideration of TID, low EF, multiple perfusion defects, lung uptake and abnormal LV wall motion, the MPI study identified $83 \%$ of the patients with LM disease as being at high risk. Similar results regarding underestimation of the extent of CAD by perfusion defects were reported by Lima and associates in a study of 143 patients undergoing ICA and SPECT ${ }^{5}$ and having three vessel CAD ( $250 \%$ stenosis). They found that $18 \%$ of patients with three vessel CAD had no perfusion abnormality on SPECT-MPI and $36 \%$ had a single territory perfusion defect. They reported improved identification of multivessel abnormality by combined assessment of clinical, perfusion and function findings from gated SPECT. Underestimation by SPECT of hemodynamically significant CAD as defined by FFR has also been reported. A recent study comparing the results of SPECT-MPI to FFR in patients with stable angina and at least two vessel CAD reported that SPECT was normal in $34 \%$ of patients with abnormal FFR measurements ${ }^{30}$.

One potential mechanism of this underlying a normal stress SPECT-MPI examination in patients with high risk CAD may be what has been termed "balanced ischemia"4-6, 30, 31. Conceptually, since SPECT-MPI detects only relative perfusion abnormality compared to a more normal region, if all myocardial regions were supplied by vessels with similar, hemodynamically significant stenoses, no relative perfusion defect would be observed. While the numbers are small, some evidence in support of this hypothesis was observed in our study. Seven of the 42 patients with high risk CAD had no detectable perfusion defect (SSS=0). Of these, 6 had coronary anatomy that would be consistent with balanced reduction of coronary flow. With exercise stress another potential mechanism of this underestimation of SPECT-MPI may be failure to achieve and adequate level of stress during exercise. While not statically significant, $20 \%$ of patients with high risk CAD did not achieve $85 \%$ of \%MPHR, and this prevalence was two times higher than that of those with no CAD. With pharmacologic stress the influence of caffeine intake not reported by the patient could reduce the ability of SPECT MPI to produce heterogeneity of myocardial perfusion.

A moderate amount of discordance between a non-invasive method which assesses the hemodynamic responses to stress and anatomic coronary angiographic findings is expected. In a substantial proportion of patients, high grade angiographic stenoses are found not to produce abnormal stress blood flow responses as measured by invasive fractional flow reserve (FFR), now considered to be the most accurate measurement of functional significance of coronary lesions. Eighteen percent of quantitatively assessed coronary stenoses of $>70 \%$ diameter narrowing have been reported to be associated with normal $\mathrm{FFR}^{32}$. Thus, some of the patients classified as having high risk CAD or obstructive nonhigh risk CAD in this study may not have had hemodynamically significant lesions.

One of the most important findings in this current study is that the magnitude of the SSS, while below normal limits was strongly associated with high risk CAD. This observation is concordant with our previous findings with respect to prognosis ${ }^{33}$. In a study of 18,200 
patients, Abidov and associates reported a significantly worse prognosis in patients with SSS 1-3 when compared with patients with SSS $0^{33}$. A recent study demonstrated that mild TPD measurements, below the threshold for abnormality, were associated with increased mortality ${ }^{34}$. These observations provide support to the concept that SPECT-MPI studies should be interpreted by employment of an "equivocal" category, which might be ascribed to patients with mild perfusion defects, rather than simple labeling of studies in binary fashion as normal or abnormal.

TID and abnormal EF/EF response were found to be associated with high risk CAD. Unlike perfusion defects on SPECT-MPI, abnormalities regarding these variables are not dependent on comparison of a region of an abnormal stress response to a normal zone. The findings regarding TID are supported by those of a previous study by Abidov et al. ${ }^{35}$ which reported that patients with a high TID and otherwise normal SPECT-MPI or minimal perfusion defects more commonly had severe or extensive CAD incorporating $3 \mathrm{VD}$ or $>90 \%$ stenosis in the proximal LAD as defined by ICA. Some recent papers, however, have reported that TID is not a predictor of extent, severity or high risk of CAD among patients with normal $\mathrm{MPI}^{36-38}$. Regarding abnormal EF/EF response abnormalities of EF response have been shown to be related to the severity of the coronary artery stenoses as defined by ICA ${ }^{39}$.

High-intermediate/high pretest probability of CAD based on age, gender, and chest symptom, were also shown in our study to be associated with both obstructive CAD and high risk CAD in the patients with normal SPECT-MPI. These findings are concordant with those of Fujimoto et al. who investigated the relationship of a normal SPECT-MPI examination to clinical findings ${ }^{40}$. Among 58 subjects with normal SPECT-MPI, they observed that age, presence of typical angina or hypertension was associated with obstructive CAD with $\geq 75 \%$ stenosis by ICA ${ }^{40}$.

None of these features alone-SSS, TID/EF, abnormal ECG response, or pretest likelihood of CAD $\ 66 \%$--may be sufficient in a patient with normal perfusion to send the patient for ICA or to consider the patient as high risk. However, our findings suggest that the combination of clinical, MPI and functional factors could be risk factors to predict high risk CAD.

It is possible that more sophisticated computer-based approaches to analysis of SPECT-MPI examinations might improve the identification of abnormality in patients with high risk CAD. Arsanjani et al. recently explored that the diagnostic performance of MPI by a fully automated computation for detection of $\geq 70 \%$ stenosis by ICA was superior to that by a visual analysis ${ }^{12}$. They subsequently demonstrated that a machine learning algorithm that combines quantitative and functional images data with clinical information showed a better prediction of severe CAD compared to visual reading ${ }^{41}$. Combining automated computed assessment of SPECT-MPI with machine learning-including all potential data elements from historical, clinical and stress data-has the potential to improve detection of disease in patients with high risk CAD and merits further exploration.

There are several limitations in the current study. The definitions of high risk CAD and obstructive non-high risk CAD employed were based on anatomic coronary stenosis 
( $\geq 70 \%$ ), rather than on functionally significant coronary stenosis as might be assessed with FFR. It is possible that many of the associated coronary lesions may not have been hemodynamically significant ${ }^{32}$. There may be a selection bias of subjects who underwent both ICA and SPECT. Due to this bias, patients with both ICA and SPECT may have been "sicker" than the patients who were not sent to ICA. It is possible that the frequency of normal SPECT-MPI examinations in patients with anatomic high risk CAD may be higher than observed in this study. There were insufficient numbers of patients with high risk CAD to determine the impact of the type of stress on the frequency of high risk CAD in the normal SPECT population. Due to these small numbers, sub-analysis with stress variables of hemodynamics including METs, Peak/Rest HR or HR reserve which are known as prognostic markers ${ }^{27,29,42}$ was not performed. We have included patients who underwent MPI using the dual isotope protocol in order to achieve sufficient numbers of patients with high risk CAD to perform the analyses, even though this protocol is no longer used because of its high radiation dose. Gated Tl-201 was performed at rest in the patients from CedarsSinai Medical Center. Due to the poorer count statistics with Tl-201, the ejection fraction responses may not be as accurate as those obtained in the cohort studied with rest Tc-99m sestamibi. While no caffeine intake for $>12$ hours is the standard requirement for patients to undergo pharmacologic stress in both laboratories, the possibility that some of the patients might have provided incorrect information regarding caffeine intake could not be evaluated. The study did not include patients who were imaged with more recently developed highefficiency CZT detector cameras may have higher diagnostic accuracy to detect small defects than the Na-I camera used in this study. An important limitation is that the number of patients with "normal" SPECT-MPI and high risk CAD was small. Further evaluation of the findings in a larger patient population with high risk CAD is needed.

\section{Conclusion}

Several clinical, stress and SPECT-MPI findings are associated high risk CAD among patients with normal SPECT-MPI. Consideration of these factors may improve the overall assessment of the likelihood of high risk CAD in patients undergoing stress SPECT-MPI.

\section{New knowledge gained}

In this study high risk CAD was found in $42 / 580$ patients (7.2\%) undergoing ICA within 60 days after "normal" SPECT-MPI, defined by summed stress score $<4$. Several factors were predictive of high risk CAD including mild/equivocal perfusion defects which were too minimal to meet criteria for abnormality, a high TID ratio or abnormal EF/EF response, and high-intermediate/high pretest probability of CAD. The presence of more than one of these factors might alert the reader to the possibility of high risk $\mathrm{CAD}$ in these patients.

\section{Acknowledgments}

Conflict of Interest disclosure statement

Dr. Nakanishi was supported in part by research fellowship awards from the Society of Nuclear Medicine and Toho University School of Medicine, Tokyo, Japan. This research was supported in part by grants R01HL089765 and 5K23HL92299 from the National Heart, Lung, and Blood Institute/National Institutes of Health (NHLBI/NIH). Its contents are solely the responsibility of the authors and do not necessarily represent the official views of the NHLBI. Cedars-Sinai Medical Center receives royalties for the quantitative assessment of function, perfusion, and 
viability, a portion of which is distributed to some of the authors of this manuscript (Daniel S. Berman, Guido Germano and Piotr Slomka). No other potential conflict of interest relevant to this article was reported. This work was also supported by grants to Dr. Berman from the Jane and Michael Eisner, and the Diane and Guilford Glazer Foundations.

\author{
Abbreviations \\ SPECT \\ MPI \\ CAD \\ ICA \\ TID \\ Single-photon emission computed tomography \\ Myocardial perfusion imaging \\ Coronary artery disease \\ Invasive coronary angiography \\ Transient ischemic dilatation
}

\title{
REFERENCES
}

1. Hachamovitch R, Hayes SW, Friedman JD, Cohen I, Berman DS. Comparison of the short-term survival benefit associated with revascularization compared with medical therapy in patients with no prior coronary artery disease undergoing stress myocardial perfusion single photon emission computed tomography. Circulation. 2003;107:2900-2907 [PubMed: 12771008]

2. Hachamovitch R, Hayes S, Friedman JD, Cohen I, Shaw LJ, Germano G, Berman DS. Determinants of risk and its temporal variation in patients with normal stress myocardial perfusion scans: What is the warranty period of a normal scan? J Am Coll Cardiol. 2003;41:1329-1340 [PubMed: 12706929]

3. Ottenhof MJ, Wai MC, Boiten HJ, Korbee RS, Valkema R, van Domburg RT, Schinkel AF. 12-year outcome after normal myocardial perfusion spect in patients with known coronary artery disease. J Nucl Cardiol. 2013;20:748-754 [PubMed: 23912382]

4. Berman DS, Kang X, Slomka PJ, Gerlach J, de Yang L, Hayes SW, Friedman JD, Thomson LE, Germano G. Underestimation of extent of ischemia by gated spect myocardial perfusion imaging in patients with left main coronary artery disease. J Nucl Cardiol. 2007;14:521-528 [PubMed: 17679060]

5. Lima RS, Watson DD, Goode AR, Siadaty MS, Ragosta M, Beller GA, Samady H. Incremental value of combined perfusion and function over perfusion alone by gated spect myocardial perfusion imaging for detection of severe three-vessel coronary artery disease. J Am Coll Cardiol. 2003;42:64-70 [PubMed: 12849661]

6. Berman DS. Fourth annual mario s. Verani, md memorial lecture: Noninvasive imaging in coronary artery disease: Changing roles, changing players. J Nucl Cardiol. 2006;13:457-473 [PubMed: 16919569]

7. Rozanski A, Gransar H, Shaw LJ, Kim J, Miranda-Peats L, Wong ND, Rana JS, Orakzai R, Hayes SW, Friedman JD, Thomson LE, Polk D, Min J, Budoff MJ, Berman DS. Impact of coronary artery calcium scanning on coronary risk factors and downstream testing the eisner (early identification of subclinical atherosclerosis by noninvasive imaging research) prospective randomized trial. J Am Coll Cardiol. 2011;57:1622-1632 [PubMed: 21439754]

8. Diamond GA, Staniloff HM, Forrester JS, Pollock BH, Swan HJ. Computer-assisted diagnosis in the noninvasive evaluation of patients with suspected coronary artery disease. J Am Coll Cardiol. 1983;1:444-455 [PubMed: 6338081]

9. Diamond GA, Forrester JS. Analysis of probability as an aid in the clinical diagnosis of coronaryartery disease. N Engl J Med. 1979;300:1350-1358 [PubMed: 440357]

10. Montalescot G, Sechtem U, Achenbach S, Andreotti F, Arden C, Budaj A, Bugiardini R, Crea F, Cuisset T, Di Mario C, Ferreira JR, Gersh BJ, Gitt AK, Hulot JS, Marx N, Opie LH, Pfisterer M, Prescott E, Ruschitzka F, Sabate M, Senior R, Taggart DP, van der Wall EE, Vrints CJ, Zamorano JL, Achenbach S, Baumgartner H, Bax JJ, Bueno H, Dean V, Deaton C, Erol C, Fagard R, Ferrari R, Hasdai D, Hoes AW, Kirchhof P, Knuuti J, Kolh P, Lancellotti P, Linhart A, Nihoyannopoulos P, 
Piepoli MF, Ponikowski P, Sirnes PA, Tamargo JL, Tendera M, Torbicki A, Wijns W, Windecker S, Knuuti J, Valgimigli M, Bueno H, Claeys MJ, Donner-Banzhoff N, Erol C, Frank H, FunckBrentano C, Gaemperli O, Gonzalez-Juanatey JR, Hamilos M, Hasdai D, Husted S, James SK, Kervinen K, Kolh P, Kristensen SD, Lancellotti P, Maggioni AP, Piepoli MF, Pries AR, Romeo F, Ryden L, Simoons ML, Sirnes PA, Steg PG, Timmis A, Wijns W, Windecker S, Yildirir A, Zamorano JL. 2013 esc guidelines on the management of stable coronary artery disease: The task force on the management of stable coronary artery disease of the european society of cardiology. Eur Heart J. 2013;34:2949-3003 [PubMed: 23996286]

11. Berman DS, Kang X, Hayes SW, Friedman JD, Cohen I, Abidov A, Shaw LJ, Amanullah AM, Germano G, Hachamovitch R. Adenosine myocardial perfusion single-photon emission computed tomography in women compared with men. Impact of diabetes mellitus on incremental prognostic value and effect on patient management. J Am Coll Cardiol. 2003;41:1125-1133 [PubMed: 12679212]

12. Arsanjani R, Xu Y, Hayes SW, Fish M, Lemley M, Gerlach J, Dorbala S, Berman DS, Germano G, Slomka P. Comparison of fully automated computer analysis and visual scoring for detection of coronary artery disease from myocardial perfusion spect in a large population. J Nucl Med. 2013;54:221-228 [PubMed: 23315665]

13. Berman DS, Abidov A, Kang X, Hayes SW, Friedman JD, Sciammarella MG, Cohen I, Gerlach J, Waechter PB, Germano G, Hachamovitch R. Prognostic validation of a 17-segment score derived from a 20-segment score for myocardial perfusion spect interpretation. J Nucl Cardiol. 2004;11:414-423 [PubMed: 15295410]

14. Rozanski A, Gransar H, Hayes SW, Min J, Friedman JD, Thomson LE, Berman DS. Temporal trends in the frequency of inducible myocardial ischemia during cardiac stress testing: 1991 to 2009. J Am Coll Cardiol. 2013;61:1054-1065 [PubMed: 23473411]

15. Germano G, Berman DS. On the accuracy and reproducibility of quantitative gated myocardial perfusion spect. J Nucl Med. 1999;40:810-813 [PubMed: 10319755]

16. Cerqueira MD, Weissman NJ, Dilsizian V, Jacobs AK, Kaul S, Laskey WK, Pennell DJ, Rumberger JA, Ryan T, Verani MS. Standardized myocardial segmentation and nomenclature for tomographic imaging of the heart. A statement for healthcare professionals from the cardiac imaging committee of the council on clinical cardiology of the american heart association. Circulation. 2002;105:539-542 [PubMed: 11815441]

17. Berman DS, Hachamovitch R, Kiat H, Cohen I, Cabico JA, Wang FP, Friedman JD, Germano G, Van Train K, Diamond GA. Incremental value of prognostic testing in patients with known or suspected ischemic heart disease: A basis for optimal utilization of exercise technetium-99m sestamibi myocardial perfusion single-photon emission computed tomography. J Am Coll Cardiol. 1995;26:639-647 [PubMed: 7642853]

18. Slomka PJ, Nishina H, Berman DS, Akincioglu C, Abidov A, Friedman JD, Hayes SW, Germano G. Automated quantification of myocardial perfusion spect using simplified normal limits. J Nucl Cardiol. 2005;12:66-77 [PubMed: 15682367]

19. Nishina H, Slomka PJ, Abidov A, Yoda S, Akincioglu C, Kang X, Cohen I, Hayes SW, Friedman JD, Germano G, Berman DS. Combined supine and prone quantitative myocardial perfusion spect: Method development and clinical validation in patients with no known coronary artery disease. $\mathrm{J}$ Nucl Med. 2006;47:51-58 [PubMed: 16391187]

20. Germano G, Kavanagh PB, Waechter P, Areeda J, Van Kriekinge S, Sharir T, Lewin HC, Berman DS. A new algorithm for the quantitation of myocardial perfusion spect. I: Technical principles and reproducibility. J Nucl Med. 2000;41:712-719 [PubMed: 10768574]

21. Sharir T, Germano G, Waechter PB, Kavanagh PB, Areeda JS, Gerlach J, Kang X, Lewin HC, Berman DS. A new algorithm for the quantitation of myocardial perfusion spect. Ii: Validation and diagnostic yield. J Nucl Med. 2000;41:720-727 [PubMed: 10768575]

22. Mazzanti M, Germano G, Kiat H, Kavanagh PB, Alexanderson E, Friedman JD, Hachamovitch R, Van Train KF, Berman DS. Identification of severe and extensive coronary artery disease by automatic measurement of transient ischemic dilation of the left ventricle in dual-isotope myocardial perfusion spect. J Am Coll Cardiol. 1996;27:1612-1620 [PubMed: 8636545] 
23. Abidov A, Germano G, Berman DS. Transient ischemic dilation ratio: A universal high-risk diagnostic marker in myocardial perfusion imaging. J Nucl Cardiol. 2007;14:497-500 [PubMed: 17679057]

24. Germano G, Kavanagh PB, Slomka PJ, Van Kriekinge SD, Pollard G, Berman DS. Quantitation in gated perfusion spect imaging: The cedars-sinai approach. J Nucl Cardiol. 2007;14:433-454 [PubMed: 17679052]

25. Sharir T, Kang X, Germano G, Bax JJ, Shaw LJ, Gransar H, Cohen I, Hayes SW, Friedman JD, Berman DS. Prognostic value of poststress left ventricular volume and ejection fraction by gated myocardial perfusion SPECT in women and men: gender-related differences in normal limits and outcomes. J Nucl Cardiol 2006;13: 495-506. [PubMed: 16919573]

26. Min JK, Berman DS, Dunning A, Achenbach S, Al-Mallah M, Budoff MJ, Cademartiri F, Callister TQ, Chang HJ, Cheng V, Chinnaiyan K, Chow BJ, Cury R, Delago A, Feuchtner G, Hadamitzky M, Hausleiter J, Kaufmann P, Karlsberg RP, Kim YJ, Leipsic J, Lin FY, Maffei E, Plank F, Raff G, Villines T, Labounty TM, Shaw LJ. All-cause mortality benefit of coronary revascularization vs. Medical therapy in patients without known coronary artery disease undergoing coronary computed tomographic angiography: Results from confirm (coronary ct angiography evaluation for clinical outcomes: An international multicenter registry). Eur Heart J. 2012;33:3088-3097 [PubMed: 23048194]

27. Azarbal B, Hayes SW, Lewin HC, Hachamovitch R, Cohen I, Berman DS. The incremental prognostic value of percentage of heart rate reserve achieved over myocardial perfusion singlephoton emission computed tomography in the prediction of cardiac death and all-cause mortality: Superiority over 85\% of maximal age-predicted heart rate. J Am Coll Cardiol. 2004;44:423-430 [PubMed: 15261942]

28. Fletcher GF, Balady G, Froelicher VF, Hartley LH, Haskell WL, Pollock ML. Exercise standards. A statement for healthcare professionals from the american heart association. Writing group. Circulation. 1995;91:580-615 [PubMed: 7805272]

29. Abidov A, Hachamovitch R, Hayes SW, Ng CK, Cohen I, Friedman JD, Germano G, Berman DS. Prognostic impact of hemodynamic response to adenosine in patients older than age 55 years undergoing vasodilator stress myocardial perfusion study. Circulation. 2003;107:2894-2899 [PubMed: 12796141]

30. Melikian N, De Bondt P, Tonino P, De Winter O, Wyffels E, Bartunek J, Heyndrickx GR, Fearon WF, Pijls NH, Wijns W, De Bruyne B. Fractional flow reserve and myocardial perfusion imaging in patients with angiographic multivessel coronary artery disease. JACC. Cardiovasc Interv. 2010;3:307-314 [PubMed: 20298990]

31. Bateman TM, Maddahi J, Gray RJ, Murphy FL, Garcia EV, Conklin CM, Raymond MJ, Stewart ME, Swan HJ, Berman DS. Diffuse slow washout of myocardial thallium-201: A new scintigraphic indicator of extensive coronary artery disease. J Am Coll Cardiol. 1984;4:55-64 [PubMed: 6736455]

32. Tonino PA, Fearon WF, De Bruyne B, Oldroyd KG, Leesar MA, Ver Lee PN, Maccarthy PA, Van't Veer M, Pijls NH. Angiographic versus functional severity of coronary artery stenoses in the fame study fractional flow reserve versus angiography in multivessel evaluation. J Am Coll Cardiol. 2010;55:2816-2821 [PubMed: 20579537]

33. Abidov A, Hachamovitch R, Hayes SW, Friedman JD, Cohen I, Kang X, De Yang L, Thomson L, Germano G, Slomka P, Berman DS. Are shades of gray prognostically useful in reporting myocardial perfusion single-photon emission computed tomography? Circulation. Cardiovasc Imaging. 2009;2:290-298

34. Nakazato R, Berman DS, Gransar H, Hyun M, Miranda-Peats R, Kite FC, Hayes SW, Thomson LE, Friedman JD, Rozanski A, Slomka PJ. Prognostic value of quantitative high-speed myocardial perfusion imaging. J Nucl Cardiol. 2012;19:1113-1123 [PubMed: 23065414]

35. Abidov A, Bax JJ, Hayes SW, Hachamovitch R, Cohen I, Gerlach J, Kang X, Friedman JD, Germano G, Berman DS. Transient ischemic dilation ratio of the left ventricle is a significant predictor of future cardiac events in patients with otherwise normal myocardial perfusion spect. $\mathrm{J}$ Am Coll Cardiol. 2003;42:1818-1825 [PubMed: 14642694]

36. Mandour Ali MA, Bourque JM, Allam AH, Beller GA, Watson DD. The prevalence and predictive accuracy of quantitatively defined transient ischemic dilation of the left ventricle on otherwise 
normal spect myocardial perfusion imaging studies. J Nucl Cardiol. 2011;18:1036-1043 [PubMed: 21938597]

37. Halligan WT, Morris PB, Schoepf UJ, Mischen BT, Spearman JV, Spears JR, Blanke P, Cho YJ, Silverman JR, Chiaramida SA, Ebersberger U. Transient ischemic dilation of the left ventricle on spect: Correlation with findings at coronary ct angiography. J Nucl Med. 2014;55:917-922 [PubMed: 24762624]

38. Valdiviezo C, Motivala AA, Hachamovitch R, Chamarthy M, Navarro PC, Ostfeld RJ, Kim M, Travin MI. The significance of transient ischemic dilation in the setting of otherwise normal spect radionuclide myocardial perfusion images. J Nucl Cardiol. 2011;18:220-229 [PubMed: 21327596]

39. Dorbala S, Vangala D, Sampson U, Limaye A, Kwong R, Di Carli MF. Value of vasodilator left ventricular ejection fraction reserve in evaluating the magnitude of myocardium at risk and the extent of angiographic coronary artery disease: A 82rb pet/ct study. J Nucl Med. 2007;48:349-358 [PubMed: 17332611]

40. Fujimoto S, Wagatsuma K, Uchida Y, Nii H, Nakano M, Toda M, Yamashina S, Yamazaki J. Study of the predictors and lesion characteristics of ischemic heart disease patients with false negative results in stress myocardial perfusion single-photon emission tomography. Circ J. 2006;70:297303 [PubMed: 16501296]

41. Arsanjani R, Xu Y, Dey D, Vahistha V, Shalev A, Nakanishi R, Hayes S, Fish M, Berman D, Germano G, Slomka PJ. Improved accuracy of myocardial perfusion spect for detection of coronary artery disease by machine learning in a large population. J Nucl Cardiol. 2013;20:553562 [PubMed: 23703378]

42. Bourque JM, Charlton GT, Holland BH, Belyea CM, Watson DD, Beller GA. Prognosis in patients achieving $\geq 10$ mets on exercise stress testing: Was spect imaging useful? J Nucl Cardiol. 2011;18:230-237 [PubMed: 21132417] 
Cedars-Sinai Medical Center 31613patients

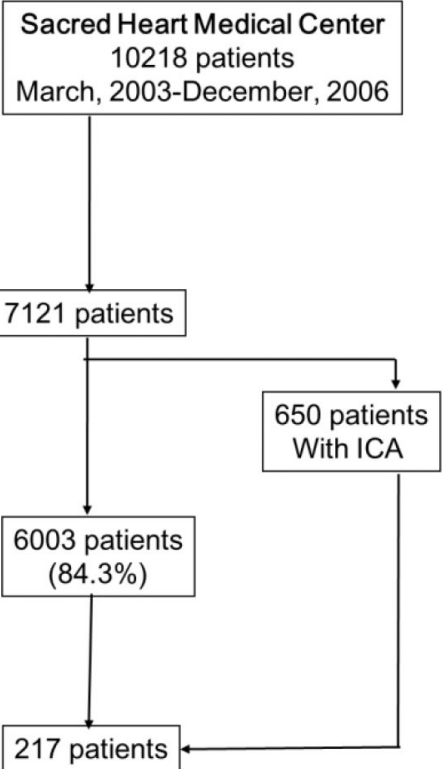

Normal SPECT and ICA

No prior MI, ICA, PTCA or CABG

Normal SPECT

19695 patients (86.6\%)
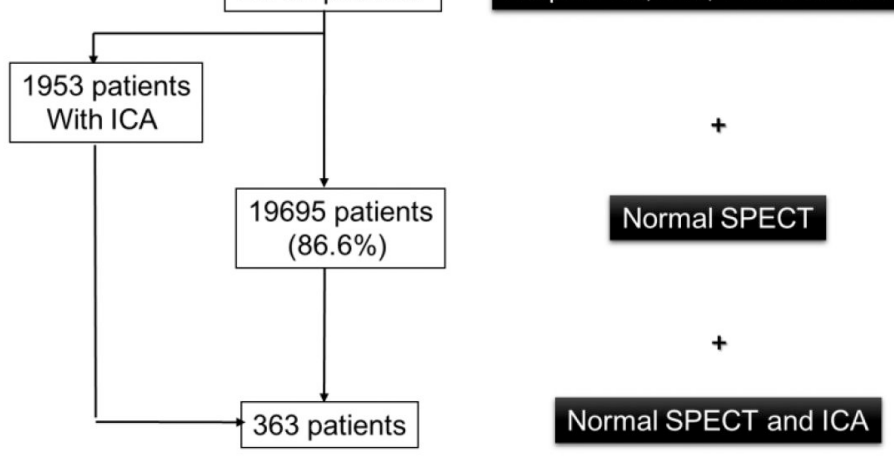

Figure 1. Patient cohort of the current study

Abbreviations: MI- myocardial infarction, ICA- invasive coronary angiography, PTCApercutaneous transluminal coronary angioplasty, CABG- coronary artery bypass graft, SPECT-single photon emission computed tomography. 


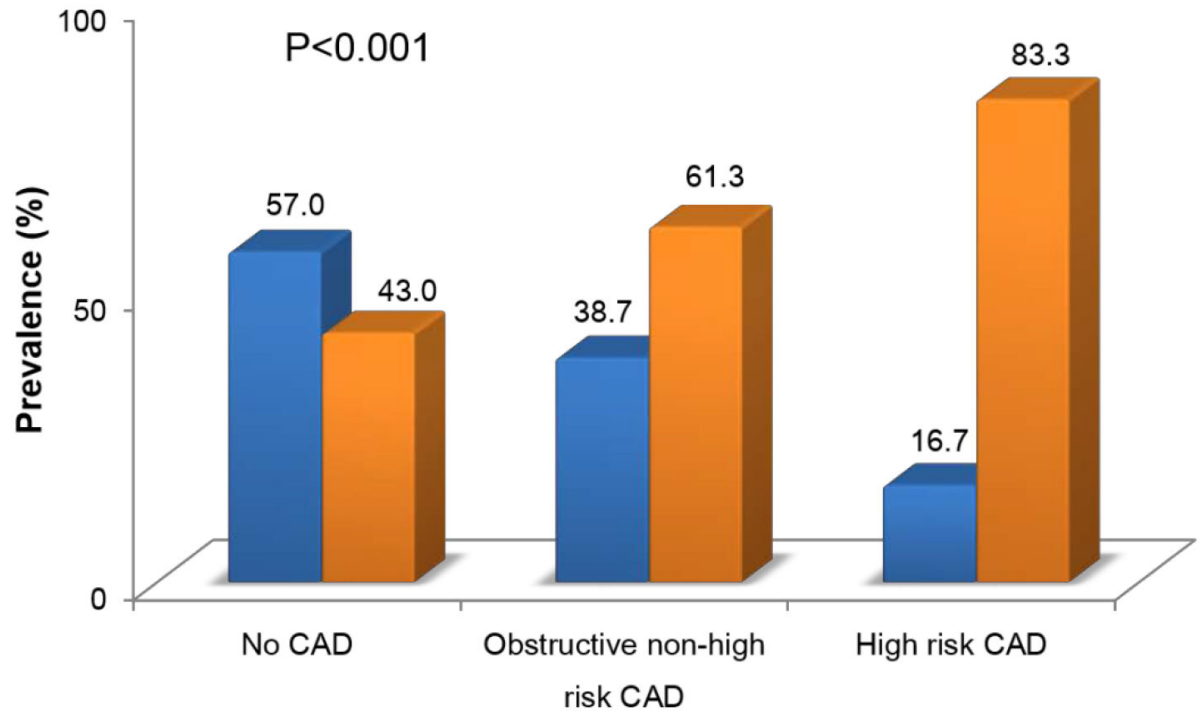

Figure 2. Prevalence of SSS 0 and 1-3 among no CAD, obstructive non-high risk and high risk CAD groups

Abbreviations: SSS- summed stress score, CAD- coronary artery disease 


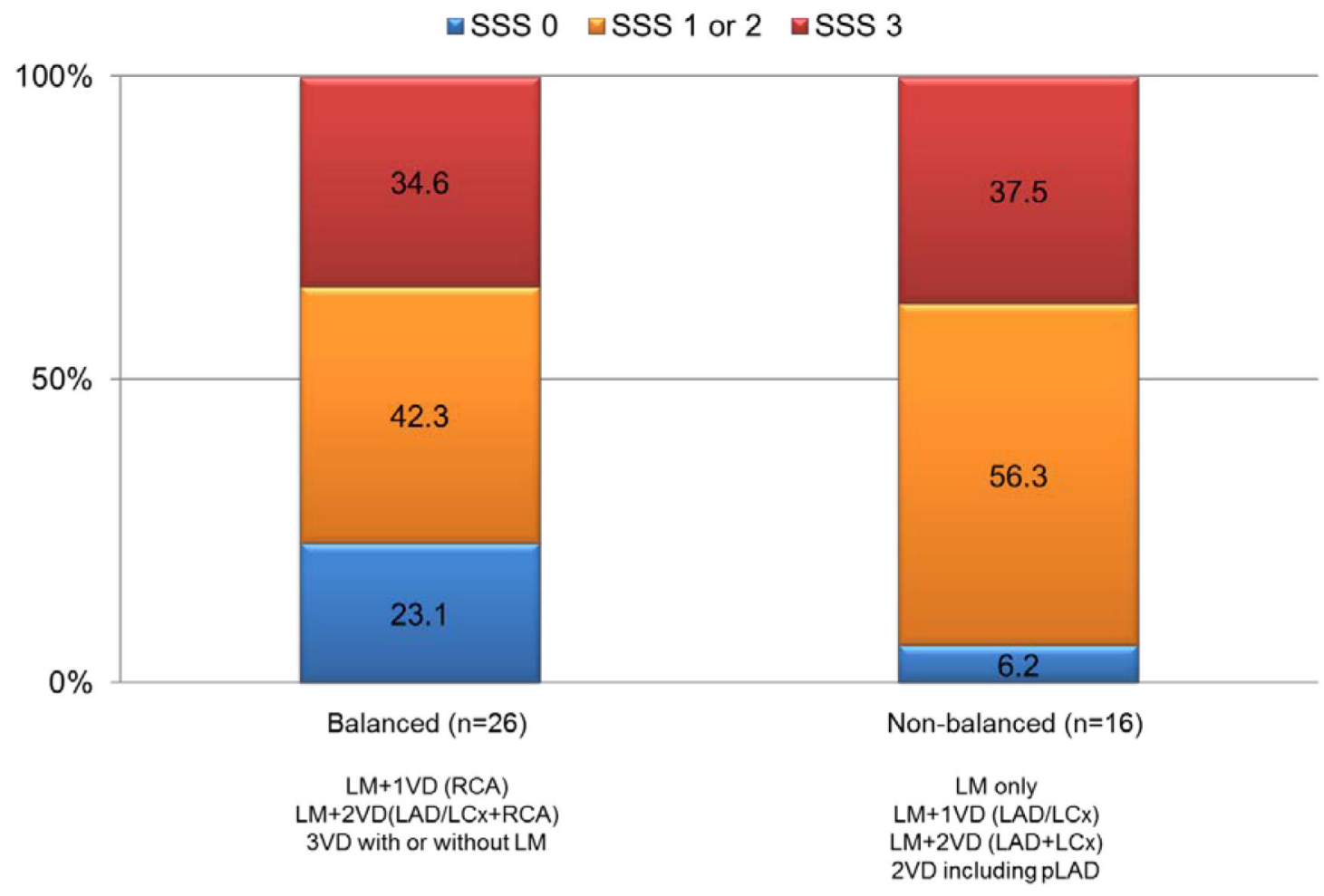

Figure 3. Frequency of SSS 0, 1 or 2 and 3 scores in 42 patients with high risk CAD among balanced and non-balanced anatomy groups.

Balanced anatomy includes LM disease + RCA with or without other stenoses or 3VD. Nonbalanced anatomy was defined as LM disease only, LM + 1VD or 2VD without RCA disease or 2VD including the proximal LAD.

Abbreviations: SPECT-MPI-single-photon emission computed tomography myocardial perfusion imaging, SSS- summed stress score, CAD- coronary artery disease, LM- left main, VD-vessel disease, LAD- left anterior descending artery, LCx- left circumflex artery, RCAright coronary artery. 


\section{Prevalence of Predictors of High Risk CAD}

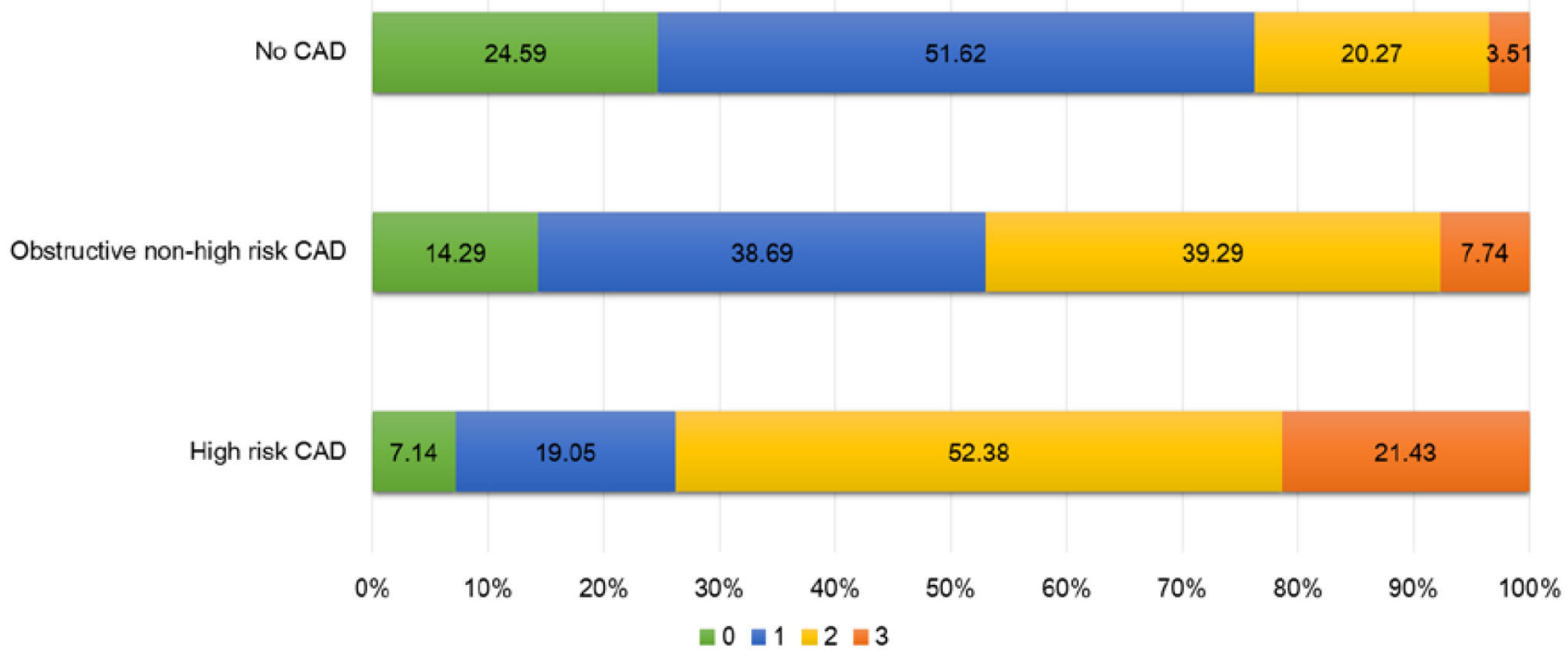

Figure 4. Prevalence of predictors of high risk CAD

Abbreviations as Figure 2. 
Table 1.

Baseline clinical characteristics among patients in the three angiographic groups

\begin{tabular}{|c|c|c|c|c|}
\hline & No CAD $(n=370)$ & $\begin{array}{l}\text { Obstructive non-high } \\
\text { risk CAD }(n=168)\end{array}$ & High risk CAD $(n=42)$ & $P$ value \\
\hline \multicolumn{5}{|c|}{ Clinical characteristics } \\
\hline Age & $62.5 \pm 12.7$ & $65.8 \pm 11.5^{*}$ & $69.6 \pm 10.4^{\dagger}$ & 0.0003 \\
\hline Gender (Male \%) & 43.8 & $54.8^{*}$ & $71.4^{t}$ & 0.001 \\
\hline Number of CAD risk factors & $1.5 \pm 1.1$ & $1.9 \pm 1.1^{\dagger}$ & $1.9 \pm 1.1^{t}$ & 0.0001 \\
\hline Hypertension (\%) & 56.8 & $67.9 \%$ & 71.4 & 0.02 \\
\hline Hypercholesterolemia (\%) & 41.6 & $60.7^{\dagger}$ & $59.5^{*}$ & $<0.001$ \\
\hline Diabetes $(\%)$ & 21.4 & 19.6 & 28.6 & 0.45 \\
\hline Smoking (\%) & 11.1 & 14.3 & 7.1 & 0.36 \\
\hline Family history (\%) & 22.7 & 29.8 & 23.8 & 0.21 \\
\hline BMI $\left(\mathrm{kg} / \mathrm{m}^{2}\right)$ & $29.2 \pm 7.2$ & $28.6 \pm 5.6$ & $26.7 \pm 8.6$ & 0.46 \\
\hline Presence of typical angina $(\%)$ & 12.7 & 19.1 & $35.7^{t^{* *}}$ & $<0.001$ \\
\hline Pretest probability of CAD (\%) & & & & 0.001 \\
\hline Low $<15 \%$ & 24.3 & 23.2 & 21.4 & 0.90 \\
\hline Intermediate $15-65 \%$ & 61.1 & 54.8 & $38.1^{\hbar}$ & 0.01 \\
\hline High-intermediate $\varangle 6 \%$ & 14.6 & $22.0 \ddagger$ & $40.5^{t^{* *}}$ & $<0.001$ \\
\hline \multicolumn{5}{|c|}{ Angiographic findings (n, \%) } \\
\hline $1 \mathrm{VD}$ & - & $114(19.7 \%)$ & - & - \\
\hline $2 \mathrm{VD}$ & - & $50(8.6 \%)$ & - & - \\
\hline $\begin{array}{l}2 \text { VD with } \geq 70 \% \text { stenosis including proximal of } \\
\text { LAD with } \geq 70 \% \text { stenosis }\end{array}$ & - & - & $8(1.4 \%)$ & - \\
\hline 3VD without LM disease & - & - & $12(2.1 \%)$ & - \\
\hline LM disease & - & - & $22(3.8 \%)$ & - \\
\hline LM only & - & - & $3(0.5 \%)$ & - \\
\hline $\mathrm{LM}+3 \mathrm{VD}$ & - & - & $7(1.2 \%)$ & - \\
\hline $\mathrm{LM}+1 \mathrm{VD}$ or $2 \mathrm{VD}$ & - & - & $12(2.1 \%)$ & - \\
\hline
\end{tabular}

Abbreviations: CAD- coronary artery disease, BMI- body mass index, VD-vessel disease, LAD- left anterior descending artery, LM- left main.

${ }^{t} \mathrm{P}<0.001$ and

${ }^{t} \mathrm{P}<0.05$ for the comparison with the no CAD group

* $\mathrm{P}<0.001$ and

**

${ }_{\mathrm{P}}^{*}<0.05$ for the comparison with the non-obstructive $\mathrm{CAD}$ group 
Table 2.

Stress characteristics among patients with exercise stress

\begin{tabular}{|c|c|c|c|c|}
\hline & No CAD (n=154) & Obstructive non-high risk CAD $(n=64)$ & High risk $\mathrm{CAD}(\mathrm{n}=18)$ & $P$ value \\
\hline Abnormal ECG response $(\%)$ & 22.1 & 28.1 & 22.2 & 0.64 \\
\hline Abnormal Clinical response (\%) & 33.1 & 45.3 & 44.4 & 0.19 \\
\hline Rest systolic BP (mmHg) & $134.3 \pm 18.3$ & $138.7 \pm 25.9$ & $140.1 \pm 16.40$ & 0.08 \\
\hline Rest HR (beats/rate) & $72.8 \pm 14.1$ & $73.9 \pm 14.3$ & $67.7 \pm 9.9$ & 0.31 \\
\hline Stress systolic BP (mmHg) & $172.0 \pm 25.9$ & $175.1 \pm 21.1$ & $168.0 \pm 24.6$ & 0.43 \\
\hline Stress heart rate (beats/rate) & $148.9 \pm 15.3$ & $145.3 \pm 16.9$ & $140.5 \pm 20.5$ & 0.18 \\
\hline BP change $(\mathrm{mmHg})$ & $37.7 \pm 25.3$ & $36.4 \pm 29.2$ & $27.9 \pm 17.9$ & 0.30 \\
\hline HR change (beats/minute) & $76.1 \pm 18.1$ & $71.4 \pm 20.1$ & $72.8 \pm 16.7$ & 0.38 \\
\hline HR reserve & $87.1 \pm 15.2$ & $84.7 \pm 16.9$ & $85.6 \pm 19.5$ & 0.76 \\
\hline HR reserve $<80 \%$ & 29.8 & 35.1 & 26.7 & 0.78 \\
\hline$\%$ MPHR & $92.8 \pm 8.2$ & $92.2 \pm 8.6$ & $91.3 \pm 12.0$ & 0.28 \\
\hline$\%$ MPHR $<85 \%(\%)$ & 11.4 & 17.5 & 20.0 & 0.36 \\
\hline Duke treadmill score & $2.1 \pm 6.4$ & $-1.9 \pm 5.7^{\dagger}$ & $-3.1 \pm 6.8^{f}$ & 0.001 \\
\hline Mets & $9.2 \pm 3.1$ & $8.6 \pm 2.7$ & $7.5 \pm 2.6$ & 0.07 \\
\hline Exercise duration & $7.7 \pm 2.7$ & $7.2 \pm 2.6$ & $6.0 \pm 2.1^{\hbar}$ & 0.01 \\
\hline Exercise duration $<6$ minutes $(\%)$ & 27.9 & 29.7 & 50.0 & 0.15 \\
\hline $\mathrm{EF}(\%)$ at rest & $65.0 \pm 12.0$ & $64.4 \pm 12.3$ & $65.2 \pm 9.2$ & 0.57 \\
\hline $\mathrm{EF}(\%)$ at stress & $65.4 \pm 10.9$ & $63.3 \pm 10.6$ & $61.2 \pm 10.2$ & 0.09 \\
\hline LVEF change & $0.4 \pm 6.9$ & $-1.0 \pm 5.8$ & $-2.5 \pm 6.0$ & 0.007 \\
\hline
\end{tabular}

Abbreviations: CAD-coronary artery disease, ECG-electrocardiogram, BP-blood pressure, HR- heart rate, Mets- metabolic equivalents, MPHRmaximum predicted heart rate, EF- ejection fraction.

${ }^{t} \mathrm{P}<0.001$ and

${ }^{t} \mathrm{P}<0.05$ for the comparison with the no CAD group

${ }^{*}<0.001$ and

${ }_{\mathrm{P}}^{*}<0.05$ for the comparison with the non-obstructive $\mathrm{CAD}$ group 
Table 3.

Stress characteristics among patients with pharmacologic stress

\begin{tabular}{|l|c|c|c|c|}
\hline & No CAD $(\mathbf{n = 2 1 6})$ & Obstructive non-high risk CAD $(\mathbf{n = 1 0 4})$ & High risk CAD $(\mathbf{n = 2 4})$ & P value \\
\hline Abnormal ECG response (\%) & 4.2 & 8.7 & $20.8^{*}$ & 0.005 \\
\hline Rest systolic BP (mmHg) & $137.8 \pm 20.7$ & $142.0 \pm 20.8$ & $144.4 \pm 25.4$ & 0.19 \\
\hline Rest HR (beats/rate) & $72.8 \pm 12.8$ & $70.7 \pm 13.0$ & $73.9 \pm 11.7$ & 0.21 \\
\hline Stress systolic BP (mmHg) & $129.9 \pm 22.3$ & $133.1 \pm 26.4$ & $135.7 \pm 30.0$ & 0.28 \\
\hline Stress heart rate (beats/rate) & $97.0 \pm 19.4$ & $93.3 \pm 21.4$ & $94.7 \pm 15.8$ & 0.28 \\
\hline BP change (mmHg) & $-7.5 \pm 20.5$ & $-8.6 \pm 27.2$ & $-9.4 \pm 26.3$ & 0.96 \\
\hline HR change (beats/minute) & $24.1 \pm 17.4$ & $22.5 \pm 16.4$ & $21.3 \pm 14.7$ & 0.50 \\
\hline Peak/Rest HR & $1.4 \pm 0.3$ & $1.3 \pm 0.2$ & $1.3 \pm 0.2$ & 0.25 \\
\hline Peak/Rest HR<1.12 (\%) & 19.3 & 19.2 & 18.2 & 1.00 \\
\hline EF $(\%)$ at rest & $65.5 \pm 12.8$ & $63.1 \pm 13.9$ & $65.0 \pm 14.6$ & 0.32 \\
\hline EF $(\%)$ at stress & $63.3 \pm 12.3$ & $61.4 \pm 13.8$ & $59.8 \pm 12.5$ & 0.33 \\
\hline LVEF change & $-1.9 \pm 6.3$ & $-1.9 \pm 5.8$ & $-5.0 \pm 4.5$ & 0.007 \\
\hline
\end{tabular}

${ }_{\mathrm{P}<0.001 \text { and }}^{\dagger}$

${ }^{\mathrm{P}}<0.05$ for the comparison with the no CAD group

*

$\mathrm{P}<0.001$ and

$* *$

$\mathrm{P}<0.05$ for the comparison with the non-obstructive CAD group 
Table 4.

SPECT-MPI characteristics among patients in the three angiographic groups

\begin{tabular}{|l|c|c|c|c|}
\hline & No CAD $(\mathbf{n}=\mathbf{3 7 0})$ & Obstructive non-high risk CAD $(\mathbf{n = 1 6 8})$ & High risk CAD $(\mathbf{n}=\mathbf{4 2})$ & P value \\
\hline SSS & $0.92 \pm 1.17$ & $1.34 \pm 1.22$ & $1.86 \pm 1.09^{\ddagger}$ & 0.0001 \\
\hline SDS & $0.82 \pm 1.10$ & $1.28 \pm 1.20^{\dagger}$ & $1.81 \pm 1.09^{\hbar^{* *}}$ & 0.0001 \\
\hline Abnormal TID & $98(26.9)$ & $56(33.5)$ & $19(45.2) \neq$ & 0.026 \\
\hline
\end{tabular}

Abbreviations: SPECT-MPI-single-photon emission computed tomography myocardial perfusion imaging, CAD- coronary artery disease, SSSsummed stress score, SDS- summed different score, TID- transient ischemic dilatation, EF- ejection fraction

${ }^{\dagger} \mathrm{P}<0.001$ and

${ }^{t} \mathrm{P}<0.05$ for the comparison with the no CAD group

* $\mathrm{P}<0.001$ and

${ }_{\mathrm{P}}^{* *}<0.05$ for the comparison with the obstructive non-high risk $\mathrm{CAD}$ group 
Table 5.

Ten-fold cross validation of clinical, stress and SPECT-MPI characteristics to predict obstructive non-high risk $\mathrm{CAD}$ or high risk $\mathrm{CAD}$.

\begin{tabular}{|l|c|c|c|c|}
\hline & \multicolumn{2}{|c|}{ Obstructive non-high risk CAD } & \multicolumn{2}{c|}{ high risk CAD } \\
\hline & OR(95\% CI) & P value & OR(95\% CI) & P value \\
\hline Model 1 & \multicolumn{2}{|c|}{ AUC=0.61 (0.56-0.66) } & \multicolumn{2}{|c|}{ AUC=0.75 (0.67-0.84) } \\
\hline Pretest probability of CAD $ð 6 \%$ & $1.70(1.0-2.8)$ & 0.037 & $3.63(1.6-8.3)$ & 0.002 \\
\hline Abnormal ECG & $1.83(1.0-3.3)$ & 0.048 & $2.67(0.8-8.5)$ & 0.095 \\
\hline Stress type (Exercise) & $0.83(0.5-1.3)$ & 0.376 & $2.93(0.4-2.2)$ & 0.871 \\
\hline SSS>0 & $2.28(1.5-3.5)$ & $<0.001$ & $7.46(2.6-21.1)$ & $<0.001$ \\
\hline Abnormal TID & $1.34(0.9-2.1)$ & 0.174 & $2.16(1.0-4.5)$ & 0.044 \\
\hline Model 2 & AUC= 0.62 (0.57-0.68) & AUC=0.79 (0.71-0.86) \\
\hline Pretest probability of CAD $\searrow 66 \%$ & $1.79(1.1-2.9)$ & 0.022 & $4.24(1.8-10.0)$ & 0.001 \\
\hline Abnormal ECG & $1.98(1.1-3.5)$ & 0.021 & $2.59(0.8-8.5)$ & 0.113 \\
\hline Stress type (Exercise) & $0.80(0.5-1.2)$ & 0.278 & $1.07(0.4-2.7)$ & 0.881 \\
\hline SSS>0 & $2.41(1.6-3.7)$ & $<0.001$ & $8.40(2.8-24.3)$ & $<0.001$ \\
\hline EF change & $0.98(0.95-1.01)$ & 0.312 & $0.93(0.9-1.0)$ & 0.023 \\
\hline
\end{tabular}

Abbreviations: OR- odds ratio, CAD- coronary artery disease, SSS- summed stress score, TID- transient ischemic dilatation, AUC- area under the curve 
Table 6.

Ten-fold cross validation of clinical, stress and SPECT-MPI characteristics to predict obstructive non-high risk $\mathrm{CAD}$, or high risk CAD in subjects with TPD. $(\mathrm{n}=390)$

\begin{tabular}{|l|c|c|c|c|}
\hline & \multicolumn{2}{|c|}{ Obstructive non-high risk CAD } & \multicolumn{2}{c|}{ high risk CAD } \\
\hline & OR(95\% CI) & P value & OR(95\% CI) & P value \\
\hline Model 1 & \multicolumn{2}{|c|}{ AUC=0.63 (0.57-0.69) } & \multicolumn{2}{|c|}{ AUC=0.74 (0.62-0.85) } \\
\hline Pretest probability of CAD $ð 66 \%$ & $2.11(1.1-4.2)$ & 0.032 & $5.26(1.8-15.2)$ & 0.003 \\
\hline Abnormal ECG & $1.51(0.7-3.4)$ & 0.323 & $2.30(0.3-16.3)$ & 0.402 \\
\hline Stress type (Exercise) & $0.63(0.4-1.1)$ & 0.090 & $0.95(0.3-3.3)$ & 0.938 \\
\hline TPD>0 & $2.36(1.2-4.5)$ & 0.008 & $6.01(1.5-22.2)$ & 0.011 \\
\hline Abnormal TID & $1.63(1.0-2.7)$ & 0.066 & $3.36(1.3-8.3)$ & 0.011 \\
\hline Model 2 & AUC=0.60 (0.54-0.66) & AUC=0.73 (0.63-0.84) \\
\hline Pretest probability of CAD $\searrow 66 \%$ & $2.18(1.2-4.0)$ & 0.012 & $6.59(2.3-18.1)$ & $<0.001$ \\
\hline Abnormal ECG & $1.63(0.7-3.7)$ & 0.234 & $1.80(0.3-10.6)$ & 0.513 \\
\hline Stress type (Exercise) & $0.60(0.4-1.0)$ & 0.048 & $1.12(0.3-3.9)$ & 0.860 \\
\hline TPD>0 & $2.29(1.2-4.4)$ & 0.014 & $5.35(1.5-18.1)$ & 0.011 \\
\hline EF change & $1.00(0.96-1.04)$ & 0.975 & $0.94(0.9-1.0)$ & 0.059 \\
\hline
\end{tabular}

Abbreviations: TPD- total perfusion defect, other abbreviations as Table 3. 